\title{
Evaluating the Effectiveness of Lumber Corset Wearing in Low Back Ache: A Rehabilitation Center Based Cross-sectional Study
}

\author{
Ahmed, I. a, Khan, MJ. b., ${ }^{*}$, Khan, AR. ${ }^{c}$, Zaman, S. ${ }^{d}$, Hawlader, MDH. ${ }^{d}$ \\ a Department of Physiotherapy, Evercare Hospital Dhaka, Dhaka, Bangladesh. \\ b Center for Noncommunicable disease Prevention Control Rehabilitation \& Research (CeNoR), Dhaka, Bangladesh. \\ c Integrated Disability Service Centre (IDSC), (JPUF), Ministry of Social Welfare, Hobigonj, Bangladesh. \\ d Department of Public Health, North South University, Dhaka, Bangladesh. \\ *Corresponding author email: khan pavel08@yahoo.com DOI: https://doi.org/10.34256/ijpefs20211 \\ Received: 27-04-2020, Accepted: 23-06-2020
}

Abstract: Patients are most commonly advised by medical practitioners even after remaining wide range of controversy regarding wearing of lumber corset in low backache (LBA). Therefore, this study aimed to determine the potential evidence of using lumber orthosis in LBA. The study adopted 50 participants ( 21 male and 29 female) ages ranging between 20 to 60 years as sample selecting randomly from September to December 2015. Outcome evaluated by calculating and presenting descriptive statistics at $0.05 \mathrm{p}$-value and $\mathrm{x}^{2}$ test with confidence intervals (95\%), Odd Ratio (OR), and Relative Risk (RR). Age and sex were not statistically significant determinants $\left(x^{2}\right.$ 1.172 , p 0.279 and $x^{2} 0.593, \mathrm{p} 0.441$, respectively). Wearing orthosis and reduce pain in a journey found as protective (RR 0.79 and RR 0.94 ) also poor relationship discovered in considering OR (OR $0.242,95 \%$ CI 0.021 2.780 and OR $0.857,95 \%$ CI $0.164-4.467)$. Our data were unable to provide adequate proof that wearing lumber corset bring any clinical or therapeutic benefit in managing LBA to the patients.

Keywords: Lumber Corset, Low Back Pain, Effectiveness, Cross-sectional study.
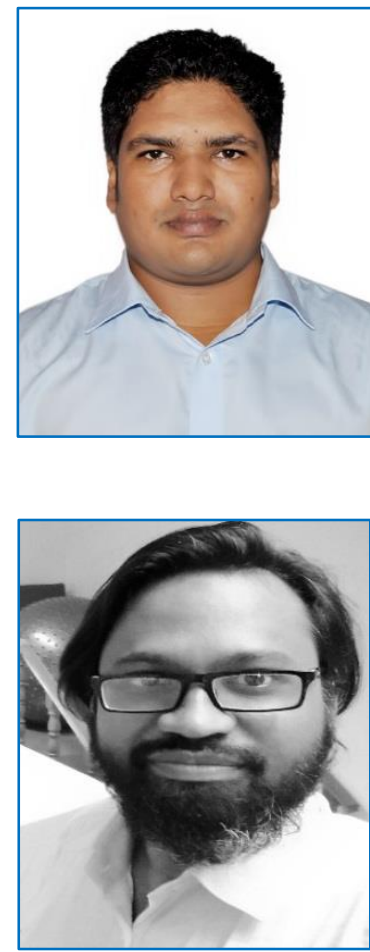

Dr. Imtiaze Ahmed BSPT, is a health care practitioner, has been graduated in physiotherapy in 2016 from the University of Dhaka. Besides completed a postgraduation diploma in sports science. Currently, working as a physiotherapist at JCI accredited Evercare Hospital Dhaka, Bangladesh.

Md Jobair Khan MPH is a leading advocate for physical therapy practitioners and rehabilitation researchers in Bangladesh. Among his many accolades is included his role as a researcher on the Center for Non-communicable disease Prevention ControlRehabilitation \& Research (CeNoR). Dr. MJ Khan has been earned the Magna Cum Laude award in the MPH program from North South University in 2018.

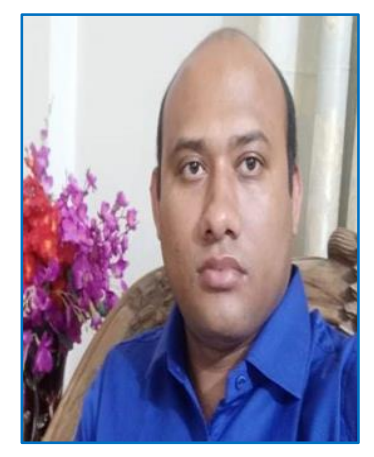

Atiqur Rahman Khan has graduated in MPH (NCD) in 2016 from ASA University Bangladesh. Before that, he has received an undergraduate degree in BSPT from the University of Dhaka, Bangladesh. Since 2013, Dr. AR Khan has been working as a clinical physiotherapist integrated disability service center (IDSC), JPUF, ministry of social welfare, Hobigonj, Bangladesh. His current research interest includes physiotherapy, public health, rehabilitation, and disability.

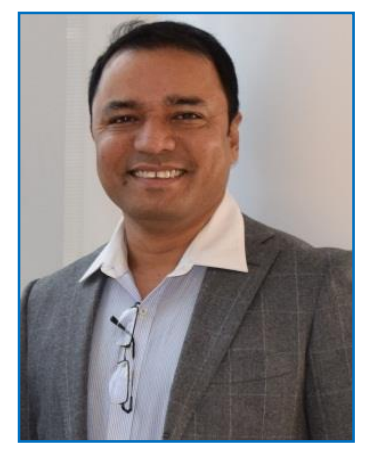

Dr. Mohammad Delwer Hossain Hawlader PhD is a medical scientific professional with having 20 years of professional experience, which included more than 14 years experience in public health research and project management and 6 years' experience of teaching in public health. Currently, he 
has been working as Associate Professor at the Dept. of Public Health at North South University (NSU). He also worked as Visiting Associate Professor in Hiroshima University, Japan and Assistant Professor at Bangladesh University of Health Sciences (BUHS). Dr. Delwer's research interest is maternal and child health, nutrition, infectious diseases, autism, disability and sports injury research.

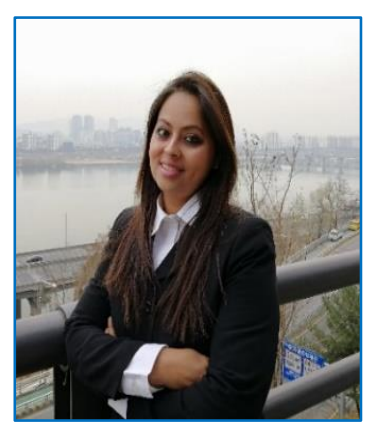

Dr. Sanjana Zaman, PhD is a Pediatrician with having 19 years of professional experience, which included clinical practice, hospital administration, research and teaching in a different positions. Currently, she has been working as Assistant Professor at Dept. of Public Health at North South University (NSU). Before that, Dr. Sanjana worked as Deputy Director at the Institute of Child Health (ICH) and Pediatric Consultant at Central Hospital Limited, Dhaka. Dr. Sanjana's research interest is child health, nutritional deficiency, reproductive health, adolescent health and infectious disease.

\section{List of Abbreviations}

LBA $=$ Low Back Ache

$\mathrm{LC}=$ Lumber Corset

EQ-5D-3L= EuroQol Group -5Dimensions - 3Severity levels

VAS= Visual Analog Scale

$\mathrm{RR}=$ Relative Risk

$\mathrm{OR}=$ Odd Ratio

$\mathrm{CI}=$ Confidence Intervals

$\mathrm{SD}=$ Standard Deviation

$\mathrm{HR}=$ Hazard Ratio

\section{Introduction}

Low Back Ache (LBA) is considering as the "20th Century Medical Disaster" condition and gain attention to greater health concerning issue [1]. It is the most frequent reason to seek a healthcare provider [2] with having many outcomes, including frequent taking time off from working-age adults $[3,4]$, rising the indirect cost [4-6], and disability [1].

Globally, LBA back pain is the most common musculoskeletal condition [7]. Hoy and colleagues [8] forecasted, sedentary lifestyle liable for increasing the number of individuals with lower back pain over the next decades. Their prophecy appears to has borne out in recent times, where the population has experienced at least one episode of lower spinal ache in their lifetime prevalence from $70 \%$ to $84 \%$ [9-13].

To treat this condition, non-operative treatments comprising rest, physiotherapy; by active therapies, for example exercise, patient education, and multimodal therapy or passive therapies like physical means, manual therapy, assistive device, injection and drug, and medication, are used before the surgical treatment $[14,15]$.

In managing backache, most patients are commonly advised to use lumber support $[16,17]$ to limit the impairment and disability, without expecting any long term adverse effect on muscle strength (18). In these days, many studies are supported by the lack of strong evidence that spinal orthosis prevents and improves the condition [19-21]. Nonetheless, the current trend among the medical practitioners is plummeting in advising to use the Lumber Corset (LC) without considering the large gaps between evidence and practices that persist in the management of LBA. Therefore, the current study is designed to investigate the effectiveness of wearing a backbelt among the Bangladeshi population for the first time to our knowledge, based on the interview response.

\section{Participants and Methods}

\subsection{Ethical issue consideration}

The research protocol for this study was approved by the ethical review board of the Bangladesh Health Professions Institute. After receiving approval, permission was taken to research the musculoskeletal unit through the department of physiotherapy, Centre for the Rehabilitation of the Paralyzed, Savar, Bangladesh. The researcher also took the individual consent form from each subject after explaining to them the aim of objectives. The subjects had the right to withdraw themselves at any point in the research.

\subsection{Subject recruitment}

This cross-sectional study included participants who had undergone treatment of the McKenzie approach for the LBA between September and December 2015. This method implemented for both the purpose of diagnosis by evaluating different directional repetitive movements and constant position, and treatment depends upon the flexion, extension, or lateral shift of the spinal direction. The investigator 
referred to the process of randomly selecting 50 healthy subjects intension to treat based on the inclusion criteria; was low back pain arising from adopting bad posture, derangement and dysfunction persist at least a month, advised to use LC, age ranging from 20 to 60 years and exclusion criteria; pregnant women, several spinal instability, trauma or fracture from a recent major accident that aggravated by movements of the lumbosacral region, and serious spinal pathology for example tuberculosis, osteoporosis, cancer, cauda equine syndrome, and ankylosing spondylitis causes fusion of the spine or major surgery in any part of the body which produced pain as an acute inflammatory reaction.

\subsection{Low Back Pain}

Low back pain is defined as the pain located in the lumbosacral region associated with some abnormality of the intervertebral discs with or without traveling pain in the lower limbs whether bilateral or unilateral [22].

\subsection{Confirmatory Diagnosis of LBP}

Participants recruited after confirmation by the fulfilling the McKenzie Institute Lumbar Spine Assessment form examination containing a) history taken from the patient, and b) physical examination through observing posture in a different position, identify lost movement, find out the neurological deficit by reflex, motor, sensory and dural signs test by the assigned physiotherapist.

\subsection{Lumber corset and wearing instruction}

It was collected from the local shop and made locally. Though there were a wide variety of lumbar supports, for instance, flexible and rigid, but we instructed to wear hard one rather not to use soft one. Flexible to wear under or over clothing, without shoulder straps, during the journey, and in the workplace in severe cases as well as those were housewives instructed to dress in household work especially work related to bending activities. Respondents were not advised to wear it the whole day or during sleeping. However, in the long journey with sitting position participants were instructed to wear the orthosis and remove every two hours for a few 15 minutes, thereafter fasten again. It was also compulsory for the person who drives their car. For bicker who ride for more than 30 minutes advised using LC as they were possessed forward ending.

\subsection{Questionnaire}

The researcher developed a questionnaire by following the EQ-5D-3L questionnaire; developed by EuroQol Group, which included five dimensions, and usually each of which has three severity levels, quantify the effect of Lumber Corset use in backache and then selected the LBA participants as the sample for data collection. It included baseline characteristics, backache, and pain before and after the use of LC related information. Data were collected through the face to face interview.

\subsection{Pain and satisfaction level measurement procedure}

LBP categorized by the combination of Visual Analog Scale (VAS) graded from 1 to 10 points and three-point pain scale (mild, moderate and chronic) of symptoms as mild or acute LBA [1-3], moderate or sub-acute LBA [4-6], and severe LBA [7-10]. Patients were asked how much they felt the pain if you scored it from 0 to 10 and then the researcher put it into the three categories. Satisfaction level was rated on a fourpoint Likert scale ranging from 1 (non-satisfaction) to 4 (strongly satisfied).

\subsection{Quality control of date}

The data quality of the participant was managed through their language. Therefore, the developed questionnaire was translated into Bengali from the English language. Data were gathered by the investigator himself. Collecting for the best quality of data the researcher, acquired important training and orientation by the supervisor and from the teaching institution. Then assembled data were input into the statistical software, thereafter check, recheck and cross check for its consistency.

\subsection{Statistical Analysis}

Data were analyzed using the Statistical Package for Social Science- 16 (SPSS Inc., Chicago, IL, USA) software. After the collection of data, all interview questions checked, excluded missing and inconsistent data, those described, as well as corrected data entered into SPSS. Continuous data reported as mean, and frequency tables used for categorical data. Chi-squire (x2) test, P-value, Relative Risk (RR) including Odd Ratios (ORs) and 95\% confidence intervals (95\% CI) were computed. Chi-square test and $\mathrm{P}$-value presented to find the significant association between dependent and independent variables. Level 
of significance accepted at $p<0.05$. Relative Risk indicated which characters were protective and ORs ( $95 \% \mathrm{CI}$ ) determined to compare the effectiveness of LC use with age in years ( $<30$ and $>30)$, gander, corset in a journey, and pain reduction in the journey.

\section{Results}

In this section, the results obtained from the analysis of the aforementioned participants are presented. More specifically, the relationship between Lumber orthosis user and low back pain is determined in this section.

\subsection{Baseline characteristics of the patients}

The study was conducted on 50 participants of having low back pain. Most of the participants were females $58 \%(n=29)$ of a high number $19(38 \%)$ of the respondents' age was less than 40 years, ranging from 31 to 40 years with a mean $( \pm S D) 41.82$ $( \pm 9.7115)$ years. About $18 \%(n=9)$ of the participants noted that they could not read and write, while, highest almost double of them $(36 \%, n=38)$ attended primary school. More than three fourth $(86 \%, n=43)$ of them were married as illustrated in Table 1.

\begin{tabular}{|c|c|c|c|}
\hline Variable & Character & n (\%) & Mean \pm SD \\
\hline \multirow[b]{2}{*}{ Sex } & Male & $21(42)$ & \multirow{6}{*}{$41.82 \pm 9.7115$} \\
\hline & Female & $29(58)$ & \\
\hline \multirow{4}{*}{ Age } & $20-30$ & $6(12)$ & \\
\hline & $31-40$ & $19(38)$ & \\
\hline & $41-50$ & $15(30)$ & \\
\hline & $50-60$ & $10(20)$ & \\
\hline \multirow[b]{2}{*}{ Marital Status } & Married & $43(86)$ & \\
\hline & Unmarried & $7(14)$ & \\
\hline \multirow{6}{*}{ Literacy Level } & No formal school & $9(18)$ & \\
\hline & Less than primary school & $3(6)$ & \\
\hline & Primary school & $18(36)$ & \\
\hline & SSC complete & $8(16)$ & \\
\hline & HSC complete & $8(16)$ & \\
\hline & Graduation complete & $4(8)$ & \\
\hline Total & & $50(100 \%)$ & \\
\hline
\end{tabular}

\begin{tabular}{|l|l|l|}
\hline \multicolumn{3}{|l|}{$\begin{array}{l}\text { Table } 2 \text { Characteristics of Low back Ache before using Lumber Corset } \\
\text { (Nature of the pain prior to lumber orthosis use) }\end{array}$} \\
\hline Variable & Character & $\mathbf{n}(\%)$ \\
\hline \multirow{4}{*}{ Region } & Central lower back & $25(50)$ \\
\cline { 2 - 3 } & Both buttock & $1(2)$ \\
\cline { 2 - 3 } & Radiate Below knee & $14(28)$ \\
\cline { 2 - 3 } & Radiate above knee & $10(20)$ \\
\hline \multirow{4}{*}{ Duration } & 1 months & $5(10)$ \\
\cline { 2 - 3 } & $2-6$ months & $6(12)$ \\
\cline { 2 - 3 } & $7-12$ months & $8(16)$ \\
\cline { 2 - 3 } & $2-3$ Years & $22(44)$ \\
\cline { 2 - 3 } & $>3$ years & $9(18)$ \\
\hline \multirow{5}{*}{ Severity } & Mild & $7(14)$ \\
\cline { 2 - 3 } & Moderate & $16(32)$ \\
\cline { 2 - 3 } & Severe &
\end{tabular}


The analysis showed in Table 2, the half $50 \%$ $(n=25)$ of the patients presented that the region of their LBA was central low back, and more than onefourth $(28 \%, n=14)$ of their pain radiated below the knee. A few $(10 \%, n=5)$ of them pain persisted one month and more than half $(54 \%, n=27)$ of them reported their severity of pain was moderate.

The statistics indicated that $46 \%(n=23)$ out of the total $(n=50)$ participants wearing a lumber belt. Among the orthosis user, assessing the pain at the beginning and the follow-up day almost equal number of cases $60.9 \%(n=14)$ and $65.3 \%(n=15)$, respectively, suffered from a moderate level, while the number of severe cases reduced in the eventual $(21.7 \%, n=5)$ from the initial $(30.4 \%, n=7)$ follow-up day. Back belts lead to reduce the pain around $60.9 \%$ ( $n=14$ ) cases during the journey. Among the four satisfactory levels, higher $47.8 \%(n=11)$ described their minimum satisfaction, although one-quarter $(26.1 \%, n=6)$ expressed dissatisfaction.

On respondent age, the non-significant difference found between $<30$ years and $>30$ years participants $(x 2=1.172, p=0.279)$, the study also revealed that participants aged greater than 30 years were 2.632 times more at risk for the LC user than those aged less than 30 years using $(\mathrm{OR}=2.632,95 \%$ $\mathrm{CI}=0.435-4.907)$.
Similar trends have revealed regarding gender and corset use in the journey, there was no statistically significant difference between male and female respondents $(x 2=0.593, \mathrm{p} 0.441$ and $\mathrm{x} 2=0.66$, $\mathrm{p}$ $0.417)$. The odds of experiencing LC used during the journey in back pain disorder was 0.857 times more probable among females than males $(95 \% \mathrm{CI}=0.164$ 4.467) and noted the negative relationship ( $p=0.854$, $\mathrm{RR}=0.79$ ). Moreover, $46 \%$ of the likelihood of using LC were dissatisfied among the participants who were female than male $(\mathrm{OR}=1.125,95 \% \mathrm{CI}=0.175-7.243)$.

\section{Discussion}

Participants who visited the medical practitioner for LBA received instruction to wear the lumber orthosis in general. The causes behind the lack of understanding of the key pathology of low backache syndromes, the overlapping symptomatology between various back problems, the deficit of diagnosis excellent objective signs and symptom of the backache syndrome, the lack of knowledge about variable course followed by numerous patients. The stabilizing effect of a lumbar orthosis is rhetorical [23] due to increases in trunk stiffness by restricting extension movement [24]. This situation catches attention and thereafter the researcher decided to evaluate the evidence of the effectiveness of using a backbelt in treating LBA and to the authors' knowledge, this is the first subjective cross-sectional study conducted in Bangladesh.

\begin{tabular}{|c|c|c|}
\hline Variable & Character & n (\%) \\
\hline \multirow[b]{2}{*}{ Lumber corset } & Yes & $23(46 \%)$ \\
\hline & No & $27(54 \%)$ \\
\hline \multirow{3}{*}{ Pain at first consultation } & Mild & $2(8.7)$ \\
\hline & Moderate & $14(60.9)$ \\
\hline & Severe & $7(30.4)$ \\
\hline \multirow{3}{*}{ Pain at final evaluation } & Mild & $3(13)$ \\
\hline & Moderate & $15(65.3)$ \\
\hline & Severe & $5(21.7)$ \\
\hline \multirow[b]{2}{*}{ Pain reduction in journey } & Yes & $14(60.9)$ \\
\hline & No & $9(39.1)$ \\
\hline \multirow{4}{*}{ Satisfaction level } & Neither & $6(26.1)$ \\
\hline & Minimally & $11(47.8)$ \\
\hline & Moderately & $5(21.7)$ \\
\hline & Strongly & $1(4.3)$ \\
\hline
\end{tabular}


Table 4 Associated factors of Low Back Ache with Lumbar Corset user among Bangladeshi population, 2015 (Significance of Lumber corset application)

\begin{tabular}{|c|c|c|c|c|c|c|c|c|c|}
\hline \multirow[t]{2}{*}{ Variable } & \multirow[t]{2}{*}{ Character } & \multicolumn{2}{|c|}{$\begin{array}{l}\text { Lumber Corset } \\
\text { Use }\end{array}$} & \multirow{2}{*}{$\begin{array}{l}\text { Rela } \\
\text { tive } \\
\text { Risk }\end{array}$} & \multirow{2}{*}{$\begin{array}{l}\text { Odd } \\
\text { Ratio } \\
\text { (OR) }\end{array}$} & \multicolumn{2}{|c|}{$\begin{array}{l}\text { 95\% Confidence } \\
\text { Interval (CI) }\end{array}$} & \multirow[t]{2}{*}{$x^{2}$} & \multirow{2}{*}{$\begin{array}{c}\text { p- } \\
\text { value }\end{array}$} \\
\hline & & Yes & No & & & Lower & Upper & & \\
\hline \multirow[t]{2}{*}{ Age } & $<30$ years & 4 & 2 & \multirow{2}{*}{1.54} & \multirow{2}{*}{2.632} & \multirow[b]{2}{*}{0.435} & \multirow[b]{2}{*}{4.907} & \multirow[b]{2}{*}{1.172} & \multirow[b]{2}{*}{0.279} \\
\hline & > 30years & 19 & 25 & & & & & & \\
\hline \multirow{2}{*}{ Gender } & Male & 11 & 10 & \multirow{2}{*}{1.27} & \multirow{2}{*}{1.558} & \multirow{2}{*}{0.503} & \multirow{2}{*}{4.803} & \multirow{2}{*}{0.593} & \multirow{2}{*}{0.441} \\
\hline & Female & 12 & 17 & & & & & & \\
\hline \multirow{2}{*}{$\begin{array}{l}\text { Use corset } \\
\text { in journey }\end{array}$} & Male & 8 & 3 & \multirow[b]{2}{*}{0.79} & \multirow[b]{2}{*}{0.242} & \multirow[b]{2}{*}{0.021} & \multirow[b]{2}{*}{2.780} & \multirow[b]{2}{*}{0.66} & \multirow[b]{2}{*}{0.417} \\
\hline & Female & 11 & 1 & & & & & & \\
\hline \multirow{2}{*}{$\begin{array}{l}\text { Pain reduce } \\
\text { in journey }\end{array}$} & Male & 6 & 5 & \multirow[b]{2}{*}{0.94} & \multirow[b]{2}{*}{0.857} & \multirow[b]{2}{*}{0.164} & \multirow[b]{2}{*}{4.467} & \multirow[b]{2}{*}{0.033} & \multirow[b]{2}{*}{0.854} \\
\hline & Female & 7 & 5 & & & & & & \\
\hline \multirow{2}{*}{$\begin{array}{l}\text { Satisfaction } \\
\text { level }\end{array}$} & Male & 3 & 8 & \multirow[b]{2}{*}{1.09} & & & & & \\
\hline & Female & 3 & 9 & & 1.125 & 0.175 & 7.243 & 0.015 & 0.901 \\
\hline
\end{tabular}

In our study, the mean ( $\pm S D$ ) age of the participants was $41.82( \pm 9.7115)$ years. We did not find any significant relationship of the patient's age $(\mathrm{x} 2=1.172, \mathrm{p}=0.279)$ and $\mathrm{LC}$ user $(\mathrm{OR}=2.632,95 \%$ $\mathrm{CI}=0.435-4.907)$. This finding did not support wearing a backbelt considering any age. Our statement supported by a randomized control trial (RCT) study of where the intervention group (back support and education) initially found to statistically decrease the rate of recurrent episodes of work-related LBA (23.1\% vs. $31.1 \%, P=0.059$ ) but when adjusted for age [Hazard Ratio (HR) 1.001, CI; 0.98-1.03, p= 0.911] measured by the electronic LC devise discovered nonsignificant relationship [25].

Investigators tried to understand the relationship between the LC user in back pain and gender, in this regard, the results revealed the nonsignificant differences ( $x 2$ 0.593, p 0.441; OR $=1.558$, $95 \% \mathrm{CI}=0.503-4.803)$, too. Similar results reflected in the trial noted that there were no statistically significant differences between groups at baseline like age, sex, race, referred pain, and education [26]. Oleske and colleagues [25] analyzed the occasion between the back belt and education receiver group with the sex $(23.1 \%$ vs. $31.1 \%)$ did not find any significant relationship (HR $0.563, \mathrm{CI} ; 0.37-0.86, \mathrm{p}=$ 0.008 ) though $p$-value (0.059) was indicating the reduction frequency of low back disorder $(23.1 \%$ vs. $31.1 \%)$.

The current result showed that the region of the pain traveled to the central lower back was half $(n=25)$ of the total cases. As to the effect of orthosis management on backache control, we did not invent any substantial association $(R R=0.79 ; \mathrm{OR}=0.242$,
$95 \% \mathrm{CI}=0.021-2.780$ ) examining the effectiveness of spinal orthosis use in the journey. A study measured the consequence of wearing the lumbosacral orthosis by electromyographic, the intervention group received standard physiotherapy and medication found all parameters remain unaffected [27].

This study revealed that pain relief during the traveling was more than half $(60.9 \%)$ in out all. Even after that, there was no significant relationship conceived between the back belt user with respect to pain reduction in the journey $(x 2=0.033, \mathrm{p} 0.854$; $R R=$ 0.94, $\mathrm{OR}=0.857,95 \% \mathrm{CI}=0.164-4.467)$. A previous study measured subjectively, in contrast to our study that reported a considerable improvement in those with LC compared with those without. While assessed objectively find that removed the corset did not differ within the groups was similar to our findings [28]. Indeed, the clinical study explained that the movement has an imperative impact on the distribution of pressure applied by the back belt [29].

Experiencing wearing orthosis was not comfortable (neither $26.1 \%$ and minimal $47.8 \%$ ) according to the opinion of the representatives. Findings in the present study regarding the satisfaction level discovered non-significant $(x 2=0.015, p=0.901$, $\mathrm{RR}=1.09 ; \quad \mathrm{OR}=1.125, \quad 95 \% \mathrm{CI}=0.175-7.243)$ relationship in response to the LC user. With the exception of the study conducted on athletes, at the time of physical training they feel protected and experienced relieving pain while wearing corset by restraining movement and decreasing stress on the injured area [30, 31].

The present study had some limitations. Firstly, it was a subjective study and secondly, involved 
a small number of patients. Therefore, further study with a higher number of samples is required for the generalization of our findings. Despite these limitations, given the fact that few recent studies were discussing the effect of LC in LBA patients, the essentiality of the present study as it offers an important contribution to the partial body of descriptive information on this topic in the literature. Besides, the strength of this study, the LBA syndrome of participants were examined and selected by the registered (Bangladesh Physiotherapy Association) and professional physiotherapist.

\section{Conclusion}

This study investigated the effectiveness of lumber corset among the patients treated with low backache and failed to prove that there was any effect of orthosis treatment on the clinical and therapeutic outcomes. Therefore, clinicians supposed to be cautious before considering prescribing lumbosacral support in similar populations. More research is desirable on the effects of LC use on the outcome measures for LBA before drawing definite conclusions regarding lumbar supports that may be most effective in managing back pain.

\section{References}

[1] R. Webb, T. Brammah, M. Lunt, M. Urwin, T. Allison, D. Symmons, Prevalence and predictors of intense, chronic, and disabling neck and back pain in the UK general population, Spine, 28 (2003) 1195-1202.

https://doi.org/10.1097/01.brs.0000067430.4916 $\underline{9.01}$

[2] Kurt T Hegmann, Russell Travis, Gunnar B.J. Andersson, Roger M Belcourt, Eugene J Carragee, Ronald Donelson, Marjorie EskayAuerbach, Jill Galper, Michael Goertz, Scott Haldeman, Paul D Hooper, James E Lessenger, Tom Mayer, Kathryn L Mueller, Donald R Murphy, William G Tellin, Matthew S Thiese, Michael S Weiss, Jeffrey S Harris, Non-Invasive and Minimally Invasive Management of Low Back Disorders, Journal of Occupational and Environmental Medicine, 62 (2020) e111-e138. https://doi.org/10.1097/jom.0000000000001812

[3] W.J. Meerding, W.I. Jzelenberg, M.A. Koopmanschap, J.L. Severens, A. Burdorf, Health problems lead to considerable productivity loss at work among workers with high physical load jobs, Journal of Clinical Epidemiology, 58 (2005) 517-523.

https://doi.org/10.1016/j.jclinepi.2004.06.016

[4] L.A. Lars, C. Thomas, B. Hermann, H. Andreas, Threshold of Musculoskeletal Pain Intensity for Increased Risk of Long-Term Sickness Absence among Female Healthcare Workers in Eldercare, PLOS ONE, 7 (2012) 41287.

https://doi.org/10.1371/journal.pone.0041287

[5] L.V. Mitchell, F.H. Lawler, D. Bowen, W. Mote, P. Asundi, J. Purswell, Effectiveness and costeffectiveness of employer-issued back belts in areas of high risk for back injury, Journal of Occupational and Environmental Medicine, 36 (1994) 90-94.

[6] M.W. VanTulder, B.W. Koes, L.M. Bouter, A costof-illness study of back pain in The Netherlands. Pain, 62 (1995) 233-240.

https://doi.org/10.1016/0304-3959(94)00272-g

[7] R.L. Milhous, L.D. Hough, J.W. Frymoyer, J.M. Ruess, R.M. Gallagher, D.G. Wilder, P.W. Callas, Determinants of vocational disability in patients with low back pain, Archives of Physical Medicine and Rehabilitation, 70 (1989) 589-593.

[8] D. Hoy, C. Bain, G. Williams, L. March, P. Brooks, F. Blyth, A. Woolf, T. Vos. R. Buchbinder, A systematic review of the global prevalence of low back pain. Arthritis \& Rheumatism, 64 (2012) 2028-2037.

\section{https://doi.org/10.1002/art.34347}

[9] J.D. Cassidy, L.J. Carroll, P. Côté, The Saskatchewan health and back pain survey: the prevalence of low back pain and related disability in Saskatchewan adults, Spine, 23 (1998) 18601867.

\section{https://doi.org/10.1097/00007632-199809010-} $\underline{00012}$

[10] F. Balague, A.F. Mannion, F. Pellise, C. Cedraschi, Non-specific low back pain, The Lancet, 379 (2012) 482-491.

https://doi.org/10.1016/S0140-6736(16)30970-9

[11] J. Lurie, C. Tomkins-Lane, Management of lumbar spinal stenosis, BMJ, 352 (2016) h6234. https://doi.org/10.1136/bmj.h6234

[12] M.W. vanTulder, B.W. Koes, L.M. Bouter, Conservative treatment of acute and chronic nonspecific low back pain: A systematic review of randomized controlled trials of the most common interventions, Spine, 22 (Phila Pa 1976) 2128-2156.

https://doi.org/10.1097/00007632-199709150$\underline{00012}$ 
[13] M.W. vanTulder, B. Koes, A. Malmivaara, Outcome of non-invasive treatment modalities on back pain: an evidence-based review, European Spine Journal, 15 (2006) S64-S81. https://dx.doi.org/10.1007\%2Fs00586-0051048-6

[14] S. Negrini, G. Imperio, J. Villafañe, F. Negrini, F. Zaina, Systematic reviews of physical and rehabilitation medicine Cochrane contents, Part 1, Disabilities due to spinal disorders and pain syndromes in adults, European Journal of Physical and Rehabilitation Medicine, 49 (2013) 597-610.

[15] Lomas-Vega R, Garrido-Jaut M, Rus A, del-PinoCasado R, Effectiveness of Global Postural Reeducation for Treatment of Spinal Disorders, American Journal of Physical Medicine \& Rehabilitation, 96 (2017) 124-130.

https://doi.org/10.1097/phm.0000000000000575

[16] J.T. Wassell, L.I. Gardner, D.P. Landsittel, J.J. Johnston, J.M. Johnston, A prospective study of back belts for prevention of back pain and injury, JAMA, 284 (2000) 2727-2732.

[17] T.R. Dillingham, Lumbar supports for prevention of low back pain in the workplace, JAMA, 279 (1998) 1826-1828.

https://doi.org/10.1001/jama.279.22.1826

[18] N. Sato, M. Sekiguchi, S. Kikuchi, H. Shishido, K. Sato, S. Konno, Effects of long-term corset wearing on chronic low back pain, Fukushima Journal of Medical Science ${ }_{L} 58$ (2012) 60-65. https://doi.org/10.5387/fms.58.60

[19] I.C. vanDuijvenbode, P. Jellema, M.N. van Poppel, M.W. van Tulder, Lumbar supports for prevention and treatment of low back pain, Cochrane Database of Systematic Reviews, 2008 (2008) CD001823.

https://doi.org/10.1002/14651858.cd001823.pub3

[20] P. Jellema, M.W. van Tulder, M.N. van Poppel, A.L. Nachemson, L.M. Bouter, Lumbar supports for prevention and treatment of low back pain: a systematic review within the framework of the Cochrane Back Review Group, Spine, 26 (2001) 377-386.

https://dx.doi.org/10.1097/00007632200102150-00014

[21] A.V. Bataller-Cervero, J. Rabal-Pelay, J.E. RocheSeruendo, B. Lacarcel-Tejero, A. AlcazarCrevillen, J.A. Villalba-Ruete, C. Cimarras-Otal, Effectiveness of lumbar supports in low back functionality and disability in assembly-line workers, Industrial health, 57 (2019) 588-595.
https://dx.doi.org/10.2486\%2Findhealth.2018$\underline{0179}$

[22] A. Frank, Low back pain, education and debate, BMJ, 306 (1993) 901-909.

https://doi.org/10.1136/bmj.306.6882.901

[23] D. Buchalter, N. Kahanovitz, K. Viola, S. Dorsky, M. Nordin, Three-dimensional spinal motion measurements, Part 2: a noninvasive assessment of lumbar brace immobilization of the spine, Journal of Spinal Disorders, 1 (1988) 284-286.

https://doi.org/10.1097/00002517-198800140$\underline{00001}$

[24] T. Terai, H. Yamada, K. Asano, A. Nawata, T. Iwasaki, T. Henmi, Effectiveness of three types of lumbar orthosis for restricting extension motion, European Journal of Orthopaedic Surgery and Traumatology, 24 (2014) S239S243.

https://doi.org/10.1007/s00590-014-1446-8

[25] D.M. Oleske, S.A. Lavender S, G.B.J. Andersson G, M.M. Kwasny, Are Back Supports Plus Education More Effective Than Education Alone in Promoting Recovery From Low Back Pain? Results From a Randomized Clinical Trial, Spine, 32 (2007) 2050-2057.

https://doi.org/10.1097/brs.0b013e3181453fcc

[26] D.C. Morrisette, J. Cholewicki, S. Logan, G. Seif, S. McGowan, A randomized clinical trial comparing extensible and inextensible lumbosacral orthoses and standard care alone in the management of lower back pain, Spine (Phila $\mathrm{Pa}$ 1976), 39 (2014) 1733-1742. https://doi.org/10.1097/brs.0000000000000521

[27] M. Samania, Z.R. Shirazib, M. Hadadic, S. Sobhanib, A randomized controlled trial comparing the long-term use of soft lumbosacral orthoses at two different pressures in patients with chronic nonspecific low back pain, Clinical Biomechanics, 69 (2019) 87-95.

https://doi.org/10.1016/j.clinbiomech.2019.07.003

[28] R. Million, K.H. Nilsen, M.I.V. Jayson, R.D. Baker, Evaluation of low back pain and assessment of lumbar corsets with and without back supports, Annals of the Rheumatic Diseases, 40 (1981) 449-454.

https://dx.doi.org/10.1136\%2Fard.40.5.449

[29] B. Bonnaire, W-S. Han, P. Calmels, R. Convert, J. Molimard, Parametric Study of Lumbar Belts in the Case of Low Back Pain: Effect of Patients' Specific Characteristics, 22nd International Conference on Medical Image Computing and 
Computer-Assisted Intervention; 2019 Oct 22; Shenzhen, China. (2019) 43-59. 〈hal-02324625〉. https://dx.doi.org/10.1007/978-3-030-15923-8 4

[30] K. Sairyo, S. Katoh, T. Sasa, N. Yasui, V.K. Goel, S. Vadapalli, A. Masuda, A. Biyani, N. Ebraheim, Athletes with unilateral spondylolysis are at risk of stress fracture at the contralateral pedicle and pars interarticularis: a clinical and biomechanical study, American Journal of Sports Medicine, 33 (2005) 583-590.

https://doi.org/10.1177\%2F0363546504269035

[31] J. Perry, The use of external support in the treatment of low-back pain, Report of the Subcommittee on Orthotics of the Committee on Prosthetic-Orthotic Education, National Academy of Sciences, National Research Council, Journal of Bone and Joint Surgery, 52 (1970) 14401442.

\section{Acknowledgement}

The authors would like to express their gratitude to all participants for their patience and assistance at the time of the interview.

\section{Informed consent}

All participants gave written informed consents to participate in this study.

\section{Funding}

No funding was received for conducting this research.

\section{Conflict of interest}

None of the authors have any conflicts of interest to declare.

\section{About The License \\ (C) The author(s) 2020. The text of this article is open access and licensed under a Creative Commons Attribution 4.0 International License}

